\title{
WITNESSING FROM HERE:
}

\author{
SELF-AWARENESS FROM A \\ BODILY VERSUS EMBODIED \\ PERSPECTIVE
}

\section{AARON HENRY}

EVAN THOMPSON

Is every conscious experience characterized by a sense of self or are there experiences that lack this feature? Does the sense of self entail the reality of a self or might the self be an illusion? Although the first question is phenomenological and the second one metaphysical, it is common to give the same answer to both. Aaron Gurwitsch's classic distinction between egological versus nonegological theories of consciousness clearly displays this broad tendency (Gurwitsch 1966). Egological theories affirm that every conscious experience fundamentally includes the awareness of an ego as the subject of the experience. Nonegological theories deny this claim and maintain that unreflective conscious experience is fundamentally ownerless or anonymous or impersonal. Both sides agree, however, that an answer to the metaphysical question of the self's existence presupposes an answer to the phenomenological question about how experience is structured. In this way, phenomenology is taken to guide metaphysics. ${ }^{1}$

\footnotetext{
1 Cf. Galen Strawson (1997): "Here I think there is a fundamental dependence: metaphysical investigation of the nature of the self is subordinate to phenomenological investigation of the sense of
} 
Egological and nonegological theories come in various forms. For example, Kant argued that in order to account for the unity of experience, we must posit a nonexperiential ego whose synthetic activity confers unity upon an otherwise heterogeneous and chaotic stream of experience. Such an argument is transcendental; it claims that the concept of self is a presupposition for meaningfully structured experience. John Searle (2000) has recently advanced a similar argument: in his view, the unity of consciousness and the logical form of explanations of volitional action require the postulation of an irreducible self in addition to the sequence of experiences. Nonegological theorists, most notably Sartre (1991) in his Transcendence of the Ego, have responded to these kinds of considerations by rejecting the inference to an experience-transcendent principle of unity. Sartre argued that experience has no need of such an external principle of organization. Following Husserl, he maintained that consciousness as a temporal flow is self-unifying and that it is precisely this feature of consciousness that obviates an appeal to a transcendental ego. ${ }^{2}$ The ego, according to Sartre, rather than being an ever-present subject of experience, appears only as an object of reflection. When unreflectively immersed in an activity, experience involves no awareness of an ego; in this way, experience is ownerless and impersonal.

In recent years, a growing number of philosophers have become interested in how these themes from Western philosophy, arising especially from phenomenology, intersect with themes concerning selfhood and consciousness from Indian philosophy (Siderits, Thompson \& Zahavi 2011). In this chapter, we aim to contribute to this cross-cultural analysis. Our approach here will be to assess critically, from the perspective of a Western phenomenological treatment of bodily subjectivity, one recent presentation of a nonegological view of consciousness inspired by early Indian Buddhism.

In an important and innovative study, Miri Albahari (2006) offers an original and forceful defense of a nonegological view of consciousness. Drawing on a novel and controversial interpretation of early Indian Buddhism, Albahari argues that the self we habitually take ourselves to be is an illusion. Our everyday sense of self is that of a bounded subject that is a personal owner of experiences and a controlling agent of actions, but in reality there is no self that possesses these attributes of ownership and executive control. Rather, the impression of self arises from a process of identification with transitory mental and bodily experiences as 'me' or 'mine'. In contrast with standard interpretations of early Indian Buddhism,

the self. There is a strong phenomenological constraint on any acceptable answer to the metaphysical question which can be expressed by saying that the factual question 'Is there such a thing as the mental self?' is equivalent to the question 'Is any (genuine) sense of the self an accurate representation of anything that exists?'

2 Husserl had himself maintained a nonegological theory in his Logical Investigations but then later revised his account of consciousness to include the transcendental ego as an invariant structure of the stream of intentional experiences. For discussion, see Zahavi (2005: 32-36, 130-132). 
however, and unlike other no-self theorists, Albahari affirms the experiential reality of a 'witnessing subject'. She thus distinguishes between a mere 'subject' of experience and a full-blown 'self'. The self, in her view, is a specific kind of subject that exhibits the property of 'boundedness', where 'boundednes' refers to the condition of being ontologically distinct with a unique personal identity that separates it from all other things (Albahari 2006: 90-91). Whereas being a subject of experience is simply a matter of instantiating an impersonal perspectival awareness of the world, the experience of selfhood additionally involves a sense of unique 'personal ownership' or 'my-ness'. It is this sense of being an ontologically distinct personal owner of experiences that Albahari argues is an illusion generated by desire-driven identification. If one could remove the deep-seated psychological 'craving' for me and mine that drives the process of identification, one would thereby remove the illusion of selfhood and realize the inherently ownerless structure of experience.

In what follows, we propose an account of consciousness that challenges this kind of nonegological view, in particular its sharp distinction between subject and self. Given the notion of a subject of experience-understood minimally as the instantiation of a perspectival awareness of the world-we need to investigate the relation such a subject bears to the body as the phenomenal locus of that awareness. Two broad options seem available. On the one hand, we can view the body as an object that belongs, in some special way, to an essentially mental subject. On the other hand, we can view the body as constituting the subject of experience. As Dorothee Legrand (2006) notes, whereas the first view can allow that the subject of experience is embodied, the second view holds that the subject is constitutively bodily.

With Legrand (2006, this volume), we contend that the subject of experience is a bodily subject and not merely an embodied one. This commitment underlies our evaluation of Albahari's nonegological position. Specifically, we will argue that in order to be a subject of experience even in the minimal sense of 'witnessing-froma-perspective', one must be prereflectively aware of oneself as a living body, i.e., one must be a bodily subject (Thompson 2007). If this view is correct, then it casts doubt on Albahari's proposed distinction between subject and self. The phenomenon of prereflective bodily self-awareness entails a basic experience of boundedness between one's subjective body and the phenomenal world with which one is bodily engaged. Consequently, by Albahari's own criteria, simply being a subject of experience will involve a basic sense of self.

In challenging Albahari's account, we intend to defend the necessary presence of a minimal bodily sense of self as a constitutive feature of perspectival awareness of the world. Dan Zahavi (2005, this volume) has recently argued that the distinctive first-personal way experiences are subjectively given and lived-through reveals them immediately as mine or for-me. According to Zahavi, this ubiquitous structural feature of experience, which pertains to how experience is given rather than what it is about, suffices to establish the experiential reality of a minimal self. Related to this line of thought, our argument will be (i) transcendental, in that it 
will aim to identify a structural feature of consciousness without which experience of the world could not occur, and (ii) phenomenological, insofar as the self whose existence we will be affirming is one given in bodily experience of the world. Focusing on the nature of prereflective bodily self-awareness, we will argue that the processes responsible for one's egocentric bodily perspective on the world are simultaneously responsible for the formation of a minimal bounded self in the form of a living bodily subject of experience.

One final introductory remark is in order. Our aim here is not to defend an egological account of consciousness if that means an account according to which the unity of consciousness requires the postulation of an unconstructed ego (an ego not constructed by the stream of intentional experiences). ${ }^{3}$ Rather, our concern is to show that perspectival awareness of the world already involves a kind of prereflective bodily self-awareness and hence bodily selfhood that Albahari's nonegolgoical account misses. If our account is correct, then although the experience of being a bounded self may not be unconstructed, it is not therefore an illusion.

\section{The 'Two-Tiered Illusion of Self'}

One of the distinctive features of Albahari's study is that she offers a detailed analysis of the self we normally and unreflectively take ourselves to be. According to her analysis, we habitually assume that we are "a conscious subject that is unified, happiness-seeking, unbrokenly persisting, [an] ontologically distinct or bounded ' $m e$ ' who is an owner of experiences, thinker of thoughts, and agent of actions" (2006: 2). So understood, the self is fundamentally a subject of experience; it is that to which objects of experience are phenomenally presented, where 'object' is understood as anything upon which one can direct attention. A number of additional features, however, characterize the kind of subject we habitually take the self to be. As an experiential subject, the self is 'elusive to its own attentive purview' (2006: 110-111, our emphasis). Because the self is the attending subject, it cannot show up fully as an object of attention. Nevertheless, we implicitly regard this

\footnotetext{
3 At least on Zahavi's reading, Husserl's transcendental ego would not fit this notion of an unconstructed ego: "although the ego must be distinguished from the experiences in which it lives and functions, it cannot exist in any way independently of them. It is a transcendence, but in Husserl's now famous phrase, it is a transcendence in the immanence" (2005: 131). Zahavi goes on to interpret this phrase as involving the following idea: "Whereas we live through a number of different experiences, the dimension of first-personal experiencing remains the same. In short, although the self, as an experiential dimension, does not exist in separation from the experiences, and is identified by the very first-personal givenness of the experiences, it may still be described as the invariant dimension of firstpersonal givenness throughout the multitude of changing experiences" (2005: 132).
} 
elusive subject as having a definite boundary, i.e., as being 'ontologically distinct' and separate from everything that is not experienced as part of the self (2006: 90). We also take this bounded subject to be unified in all of its experiences and roles (as agent, thinker, owner, and so on). In other words, there appears to be only one point of view to which a multitude of experiences are presented, both at a time (synchronically) and over time (diachronically) (2006: 111-112). We also assume the self to be both unbroken - numerically identical through changing experiencesand invariable - qualitatively the same over time (2006: 113, 117). Finally, we habitually assume the self to be unconstructed (2006: 118). In other words, we believe that our self exists prior to and stands apart from particular experiences, that the self is their precedent rather than their product. In this way, the phenomenal content belonging to our sense of self seems 'unborrowed' and not 'contributed to' by the intentional objects of experience.

Although Albahari regards the self as a whole to be illusory, she does not regard all of its features as illusory. In her view, many of the properties mistakenly attributed to the self are intrinsic to nonegological consciousness. These properties include elusiveness, unity, unbrokenness, invariability, and unconstructedness. ${ }^{4}$ To appreciate this distinctive version of the nonegological conception of consciousness, we need to examine Albahari's distinction between 'subject' and 'self' as well as the related distinctions between different kinds of ownership.

Albahari defines a subject as "witnessing as it presents from a psycho-physical (hence spatiotemporal) perspective" (Albahari 2006: 8). "Witnessing" refers to an invariant property of apprehension or observation that she argues is present in all experience. Witnessing is modality-neutral, i.e., it is not tied to a particular mode of cognition, and it has its own phenomenal character, i.e., there is something it is like simply to be aware. ${ }^{5}$ All conscious experiences, according to Albahari, share this feature of witnessing presence or awareness. Thus the phenomenal content of an experience is not exhausted by the objects of which we are aware, whether focally or peripherally (2006: 143-145). Moreover, with the exception of boundedness, witness consciousness truly exhibits all of the features that we mistakenly attribute to the self, including elusiveness, unity, unbrokenness, invariability, and unconstructedness (2006: 166).

4 Albahari presents this aspect of her view as an (unorthodox) interpretation of Theravada Buddhism, but we would argue it is much closer to the later Indian school of Advaita Vedanta than to early Indian Buddhism.

5 In Analytical Buddhism, Albahari distinguishes between witness consciousness and awareness, where the former refers only to "the mode-neutral awareness" present in all acts of phenomenal apprehension and the latter incorporates the dimension of intrinsic phenomenal character. In a more recent paper (Albahari 2009), she collapses the distinction so that witness consciousness is now the same as what she called awareness in her book. We will follow her in treating them synonymously. For more on the Indian philosophical origin and development of the concept of witness consciousness, see Gupta (1998). 
Albahari also discusses the role of ownership and distinguishes between 'perspectival ownership' and 'personal ownership'. ${ }^{6}$ For a subject to own something perspectivally is for it to appear to the subject in a way that it does not appear to any other subject. When I have a toothache, for example, it presents itself to my perspective in a distinctive way. In the case of outer objects of perception, what is perspectivally owned is not the object, but the specific manner through which the object appears to the subject (2006: 53). Personal ownership, however, occurs when one identifies with an experience or experienced object as the owner of that experience or object. Personal ownership involves the reflexive assumption, made by the witnessing subject, that various psychophysical attributes either belong to or constitute it as a subject. In this way, these attributes appear as part of the subject rather than as objects within the subject's attentive purview (2006: 56). In making this assumption, one comes to regard these attributes as mine or as part of me. Albahari also conjectures that this process of identification induces and is induced by emotions of craving, which represent a bounded self as part of their content (2006: 205).

It is with the onset of feelings of personal ownership, Albahari maintains, that one also finds a sense of self (2006: 73). Once one identifies with an object of experience, such that it is perceived as belonging to or as part of the subject, a felt boundary emerges between what is self (what is felt to be mine) and what is other (what is felt to be not-mine). This felt sense of boundedness, created by identification with objects of experience, transforms the impersonal subject of experience into a subject that experiences itself as a 'substantial personal thing', i.e., a self (2006: 94). As a consequence, the features proper to witnessing awarenesselusiveness, unity, unbrokenness, invariability, and unconstructedness-that are nonillusory in themselves, are 'imported' into the sense of self. In conjunction with identification and emotions of self-concern, such importation creates the impression of a bounded personal owner who possesses the features of awareness (2006: 140).

Albahari's account thus proposes two 'feeders' that create a 'two-tiered' illusion of self: (i) a subject's awareness purports to be essentially bounded when it is not (the experience of boundedness can drop away); and (ii) the bounded self, in reality a cognitive and emotional construction, purports to harbour features that in reality belong to the unconstructed awareness. As a result, the self does not have the ontological status it purports to have, namely, being bounded or ontologically distinct as well as being the possessor of features that belong instead to the egoless awareness (2006: 72).

6 Albahari also distinguishes these from 'possesive ownership', which refers to social conventions governing personal property. We will be concerned only with perspectival and personal ownership. 


\section{Perspectival Ownership and Prereflective Self-Awareness}

Important similarities can be found between Albahari's account of subjectivity as 'perspectival ownership' and Western phenomenological accounts of subjectivity as 'prereflective self-awareness' (see Zahavi 2005; this volume). Here we call attention to these similarities in order to zero in on a crucial difference, which we discuss in the next two sections.

One of the central theses found in the phenomenological tradition is that intentionality (the object-directedness of consciousness) essentially involves selfawareness. The kind of self-awareness at issue, however, is not the reflective selfawareness that consists in a higher-order mental state taking a distinct, first-order mental state as its intentional object. Rather, it is a prereflective self-awareness by which every conscious experience manifests to itself as a conscious experience. Because this kind of self-disclosure or self-manifestation does not consist in relating to the experience as an intentional object, the self-experience is described as a prereflective and intransitive self-consciousness. Zahavi (2005) proposes that this feature of consciousness accounts for the 'first-person givenness' of conscious experience: regardless of what I am conscious of (the intentional object of my conscious state), my conscious experience manifests immediately as mine or forme. According to this conception, phenomenal consciousness is necessarily characterized by a prereflective sense of self or by what Sartre called 'ipseity' (selfhood). For Zahavi, this kind of selfhood-a prereflective selfhood prior to and more fundamental than the ego of reflection-amounts to a 'minimal self' as the subject (or subjectivity) of intentional consciousness (2005: 106).

There is thus a significant convergence between Albahari's Buddhist-inspired view of consciousness and Western phenomenological views. Both reject the 'object-knowledge thesis', according to which "all knowledge and experience must be derived from the object side of the apparent subject/object dichotomy (remembering that objects are, in principle, able to be attended to)" (Albahari 2006: 107). For Albahari (2006: 168), awareness contributes to the phenomenal content of an experience by being reflexively about itself but without being an object of attention (2006: 168). Similarly, phenomenologists maintain, in being intentionally directed toward objects, we are also prereflectively aware of the experiences through which those objects are given (see Thompson 2007: chapter 10). Finally, according to both viewpoints, the most fundamental mode of selfawareness is not to be understood as any kind of transitive or object-directed consciousness. Rather, the subject is self-aware in a tacit and non-object-directed manner in and through its being aware of the world. 
Given these similarities, it is tempting to regard Albahari's notion of the subject or 'witnessing as it presents from a perspective' as basically equivalent to the phenomenological notion of ipseity, or more precisely to Zahavi's interpretation of ipseity as a 'minimal self'. According to this reading, the 'for-me-ness' of conscious experience is a matter of being a perspectival owner of experience (as opposed to a personal owner); it is simply the observation that all subjective experiences are presented from the first-person perspective. Hence one might conclude that the disagreement between Albahari and Zahavi over the status of the self — or between other Buddhist no-self viewpoints and Husserlian phenomenology (Siderits, Thompson, and Zahavi: in press) - is largely terminological: the notion of self Albahari rejects as illusory is not the notion of self described and defended by phenomenologists. Yet, as we will now see, there is another phenomenological thesis about subjectivity that can be used to highlight an important difference between these views.

\section{Distinguishing the Bodily Subject from the (Merely) Embodied Subject}

In a famous passage of Meditation VI, Descartes states that the mental subject of experience (the thinking ego) and its body are "very closely joined" and "intermingled," "so that I and the body form a unit" (Descartes 1986: 56). On this view, although the subject of experience can be said to be embodied, it is not constitutively bodily; rather, the subject is conceived as an essentially mental being, one that simply happens to be united to this particular body rather than some other.

Some philosophers deny the Cartesian claim that a mental subject can exist without being embodied, yet still hold that the subject appears to introspective selfawareness as distinctively mental. In other words, they would argue that although the self is necessarily embodied, one is nonetheless presented to oneself in introspective self-awareness as a mental subject and not as a bodily one. For example, Sidney Shoemaker writes, "we are not presented with ourselves in introspection as bodily entities" (Shoemaker 1986), and, "when one is introspectively aware of one's thoughts, feelings, beliefs, and desires, one is not presented to oneself as a flesh and blood person, and one does not seem to be presented to one as an object at all" (Shoemaker 1984: 102).

In contrast, many phenomenologists, most notably Merleau-Ponty (1962), would reject this view.7 The subject is not merely embodied but bodily: "But I am not in

\footnotetext{
7 See also Cassam (1999; this volume), although his discussion does not differentiate between the body as subject and the body as object in the way we do here.
} 
front of my body, I am in my body, or rather I am my body" (Merleau-Ponty 1962: 150). Yet Merleau-Ponty refuses to understand the proposition "I am my body" in a materialist way, as meaning that I am (or my self is) nothing more than a certain physical object. Instead, he maintains the original position that I am a bodily subject.

This view involves several crucial ideas that depart from the conception of the subject as merely embodied. First, introspective self-awareness is not our primary mode of self-awareness; rather, we are prereflectively self-aware in world-directed perception, action, and feeling. Second, introspective self-awareness is not the only mode of self-experience that can be nonobservational, i.e., not based on being presented to oneself as an object. On the contrary, prereflective self-awareness presents the body not as an object of inner or outer perception, but rather as the subject of perception, action, and feeling (Legrand 2006; this volume). Finally, therefore, self-experience in its most basic nonobservational form presents oneself as a living bodily subject and not as a purely mental one (Thompson 2007).

Merleau-Ponty's sentence quoted above expresses these ideas. "I am not in front of my body" means that I cannot experience my body simply as an object of outer perception: "I observe external objects with my body, I handle them, examine them, walk round them, but my body itself is a thing which I do not observe; in order to be able to do so, I should need the use of a second body which itself would be unobservable" (Merleau-Ponty 1962: 104). Of course, I can, for example, look down at my hands or see my reflection in mirror, but I cannot completely objectify my body, for "I am in my body." Yet the crucial point here is not that what makes my body different from other objects is that I also happen to experience my body from within (interoceptively or proprioceptively). Rather, it is that I prereflectively and nonobservationally experience my body as the subject of my perspectival awareness of the world (including my body as an object). As Zahavi writes:

Whereas I can approach or move away from any object in the world, the body itself is always present as my very perspective on the world. That is, rather than being simply yet another perspectivally given object, the body itself is exactly that which allows me to perceive objects perspectivally ... The body is present, not as a permanent perceptual object, but as myself. Originally, I do not have any consciousness of my body as an intentional object. I am not perceiving it, I am it . . Thus, my original body-awareness is not a type of object-consciousness, is not a perception of the body as an object, but a form of immediate, prereflective, self-awareness (Zahavi 2002: 21).

In summary, according to this phenomenological line of thought, the subject of experience is a bodily subject. Bodily self-awareness, however, does not happen only when one experiences one's body as an object of inner or outer perception. On the contrary, the primary form of body awareness is not a type of transitive consciousness of the body-as-object. Rather, the primary form of body awareness is the body's intransitive self-experience as a perceiving, acting, and feeling subject - the body-as-subject (see Legrand, this volume, for further discussion). 


\section{Bodily Subjectivity and Perspectival WITNESSING}

Returning now to Albahari's nonegological view, we need to ask about the status of the body in relation to the subject of experience. Does the body belong constitutively to the unified and impersonal conscious awareness? Or is the body an inessential accompaniment of a witness consciousness that is essentially mental? In short, is the subject of experience constitutively bodily or merely embodied?

We will now present evidence to suggest that Albahari understands the subject of experience as being merely embodied. According to her view, witness consciousness is not intrinsically tied to a psychophysical perspective, for she wishes to allow for the psychological possibility of a completely perspectiveless and thus subjectless witness consciousness (2006: 9-10). On her reading, the consciousness proper to the fully liberated state of nirvana ('nibbanic consciousness') would be such a witness consciousness, i.e., a form of pure awareness that lacks any intentional object and is unconditioned by space and time (2006: 46). Albahari makes clear that her aim is not to argue for the psychological possibility of a pure subjectless witnessing unconditioned by spatiotemporal perspective. Instead, her concern is to describe the nature of the ordinary consciousness that harbours a sense of self ('pre-nibbanic consciousness') and to defend the possibility of a consciousness ridden of the sense of self but that still functions as a perspectival owner of experience ('proximate-nibbanic consciousness'). Nevertheless, the fact that she wishes to leave open the possibility of pure witnessing awareness indicates that the phenomenal character of witnessing, as it occurs in the context of the impersonal perspectival awareness (absent a sense of self), will not be inherently bodily.

Albahari might wish to say that although pure witness consciousness is not bodily in nature, the subject of experience is bodily. Recall that she defines the subject as "witnessing as it presents from a psycho-physical (hence spatiotemporal) perspective" (2006: 8). One might therefore claim that the subject, by definition, is bodily. For example, one might understand the subject as the conjoining of a witnessing awareness, itself prior to the subject-object distinction, with a bodily perspective. As a result of this union, experience would take on a subject-object structure with witnessing awareness being phenomenally located on the subjectside of experience (as Albahari says, witnessing is the 'modus operandi' of the subject). This combination would appear to generate a bodily subject insofar as the subject is partly constituted by the specific bodily perspective from which witnessing appears to emanate. Consequently, one might think that subject and body are one, not two.

Yet other considerations make this interpretation untenable. Recall that, for Albahari, an 'object' is anything that can, in principle, be attended to by a witnessing 
subject, such that whatever attention targets will be experienced as standing over and against the subject. Included in what can be a focus of attention are not only external objects, i.e., ones we experience as transcending our particular point of view, but also 'perspective-lending' aspects or features of experience, such as sensations, feelings, and qualities of awareness (e.g., drowsy or alert), which determine the subject's unique egocentric perspective on external objects (2006: 11, 14, 57-58). Thus the subject has different kinds of 'objects' available to it. On the one hand, perspective-lending objects are ones whose features pertain to the subject's phenomenal perspective; on the other hand, non-perspective lending or exernal objects pertain to the world as experienced by the subject.

Given Albahari's distinction between perspective-lending and external objects, it seems to follow that a subject that is free of the self-illusion (e.g., the arahant or enlightened person) will have an entirely objectified experience its body. At various points in the text, Albahari describes the subject's experience of its body as both a perspective-lending object and an external object (2006: 11, 14, 58). On the one hand, the body is perspective-lending in the sense that our experience of it serves to relate us to external objects; for example, bodily sensation (tactile, proprioceptive, visual, and so on) provides us with information about our relation to the external world. On the other hand, the body can also be experienced as an object belonging to the world, as when one touches oneself or sees oneself in a mirror. Albahari treats both kinds of bodily experience as experience of the body as an object: "The central point of relevance is that the object is anything that can be attended to by a witnessing subject, whether through channels that are mental, visual, auditory, gustatory, olfactory, tactile, proprioceptive, or pertaining to those channels, to the very qualia associated with each sensory or mental modality" (2006: 11, emphasis in original). Furthermore, witnessing awareness, which is the modus operandi of the subject, is distinct from any such object: "Our core concept of awareness thus conveys a type of experience-a subjective sense of presence-that is unmediated by any specific quality pertaining to objects, outer or inner. In our concept, this subjective sense of presence intrinsically qualifies the witness-consciousness that is the modus operandi of a subject" (2006: 144). Consequently, it would seem impossible for the subject to be constitutively bodily, because the body is given fundamentally as an object. As that which is aware of any such object, the subject must be essentially body-transcendent.

Albahari confirms her conception of the subject as body-transcendent when she discusses an especially subtle and "primal" mode of identification in which the subject assumes itself to be essentially (rather than contingently) confined to its unique "hemmed-in" perspective (2006: 58-59). She writes: "The self', in this context, would thus refer to those perspective-lending khandhas [psychophysical factors] as assimilated with the witnessing that shows through them" (2006: 58). Consequently, to regard one's perspective-lending body as part of the subject involves one in the illusion of subjectively being what, in reality, is a transient 
object within one's attentive purview. This assessment can be seen clearly in Albahari's analysis of the statement, "I feel healthy today." On her interpretation, the proposition expressed by this statement betrays the subject's identification with a healthy-feeling body as self. As a result, the body is felt as belonging to the subject: "a single entity in which subject and body are fused... The 'I' that claims to feel healthy seems to be a hybrid, namely the body-as-subject" (2006: 58, emphasis in original). It follows that one who is free of the sense of self can only be an embodied subject but not a bodily one. Thus, according to Albahari's view, although the experience of the body may contribute to defining the confines of one's perspectival awareness, it is not intrinsically part of that subjective awareness. ${ }^{8}$

We have now arrived at a basic disagreement between Albahari's nonegological view and the phenomenological conception of bodily subjectivity. As we have seen, phenomenologists from Husserl onward regard the original form of bodily experience not as a consciousness of the body as intentional object but rather as an intransitive (non-object-directed) and preflective bodily self-awareness. In other words, phenomenologists regard bodily self-experience as belonging on the subject-side of the subject-object distinction. In order for it to be possible to perceive a world of objects (including the body-as-object), one must be a bodily subject. According to Albahari's account, however, such body-as-subject awareness is symptomatic of a particularly subtle form of identification with the body as the self. Such an awareness reflects the fact that the body as perspective-lending object has been illicitly appropriated to the witnessing subject, such that the body's status as an object has been rendered invisible (Albahari 2006: 63, 118). According to Albahari, witnessing without a sense of self will still occur from a perspective (so long as the experience is object-involving), but it will not assume this bodily perspective to be inherent to itself (2006: 58). Another way to put this disagreement is that, on Albahari's view, the phenomenological tradition is mistaken in regarding the body as prereflectively self-aware, that is, as nonobservationally and intransitively self-aware. Rather, on her view, the perspective-lending body that we live

\footnotetext{
8 It is intriguing that Albahari chooses to describe the phenomenal character of witnessconsciousness as a 'subjective sense of presence' (2006: 144). She points out that 'presence' conveys both a spatial and temporal connotation: 'present' can mean the sense of both a spatial here and a temporal now. In our view, such a characterization of witness consciousness would be perfectly appropriate if witnessing were inherently bodily. If that were the case, then one would expect witness consciousness to be centered or rooted in a feeling of 'here' and 'now'; both express a lived bodily presence. It is, however, unclear whether Albahari intends this description to apply only to prenibbanic consciousness (which harbors a sense of self) or would also regard it as an apt description of proximate-nibbanic consciousness (i.e., the consciousness of a arahant or enlightened person). Put differently, would witness consciousness be associated with the spatiotemporal experience of the chere and now' for someone liberated from the self-illusion or is this experience simply a manifestation of the habitual tendency to identify with and thus appropriate the experience of one's bodily perspective to witness consciousness?
} 
through in our experience of the world would rather have the status of a marginal or unattended to object of awareness.

One reason this disagreement matters is that if it turns out that the subject is constitutively bodily, then it would follow that the subject is also bounded. (As we will discuss in the conclusion, however, it would not follow that its boundaries are static and fixed rather than dynamic and flexible.) As long as the body is experienced as subject, there will be a fundamental experiential distinction between self and other. Hence a sense of boundedness would be implicit in both personal and perspectival ownership; having a perspective on the world would entail a distinction between the subjective body, which one nonintentionally lives through in world-directed experience, and the objective world, toward which one is intentionally related via one's bodily self-experience. This nonillusory sense of distinctness would count against Albahari's account, according to which any experience of boundedness is illusory.

\section{Arguing for the Bodily Subject}

We will now consider why perspectival ownership requires being a bodily subject. Specifically, we will present a modified version of Sidney Shoemaker's argument that self-awareness must be based on a nonobservational awareness of oneself as subject (Shoemaker 1968).

According to Shoemaker (1968), the awareness that I have of myself as the subject of experience is not based on the perception of an object whose observed properties serve to identify it to me as myself. In order to identify an object as myself, I must find something true of the observed object that I already hold to be true of myself. In particular, I would need to have prior knowledge of a distinguishing property the observation of which allows me to identify something as myself. Such a judgment therefore presupposes some prior acquaintance with myself. Consequently, according to Shoemaker, it is impossible to claim that all instances of self-knowledge are grounded on judgments of identification without generating an infinite regress of such judgments. It is therefore not the case that one first encounters a neutral or anonymous mental state and then asks, "to whom does this mental state belong?” Instead, one's mental states are known immediately and nonobservationally as one's own. Thus, the awareness that I have of myself as the subject of experience is not based on perception or observation.

In its original form, Shoemaker's argument does not apply to Albahari, for two reasons. First, 'identification' is used differently by the two authors. By 'identification', Albahari means the act of appropriating what is in reality an object of 
experience to the subject of experience, such that it appears as assimilated with the subject's perspective on the world. Roughly, by 'identification', Shoemaker means a judgment, made on the basis of observation and inference, in which an identity is asserted between the subject of the judgment and the bearer of the property figuring in the predicate of the judgment. For example, I judge that it is John who is running, given that I know someone is running and that I identify that individual as John. Second, Albahari would grant that the subject's awareness of itself is not based on the observation of an object (Albahari 2006: 144-145, 167-169). As we mentioned above, she rejects the 'object-knowledge thesis', according to which "all knowledge and experience must be derived from the object side of the apparent subject/object dichotomy (remembering that objects are, in principle, able to be attended to)" (2006: 107). In her nonegological view, (2006: 168), the witnessing subject contributes to the phenomenal content of an experience by being reflexively about itself but without being an object of attention (2006: 168). Thus, her account is compatible with Shoemaker's argument.

Nevertheless, we can formulate an argument in terms of perspectival-ownership and the body that does apply to Albahari.9 Specifically, we can ask the following question: How is it possible for the witnessing awareness to know that it is witnessing from a perspective? To answer this question, Albahari would appeal to her distinction between perspective-lending objects and external-objects. Specifically, according to her account, it is through awareness of the former that there can be awareness of the latter. In this way, perspective-lending objects provide the subject's access to the world; they constitute the medium for world-directed experience.

The trouble with this explanation is that it is difficult to understand how witness consciousness could ever acquire the understanding that what it apprehends in experience is a perspective on an objective world and hence that it occupies the role of a subject of experience. We contend that it is only if the witnessing awareness already knew itself to be a perspective-holder, specifically a body in relation to which external objects are egocentrically situated, that it would be possible to identify which aspects of experience are distinctively perspective-lending. The subject's ability to identify some item of experience as perspective-lending presupposes a prior prereflective awareness of itself as located here in this lived body. If awareness did not include an immediate and non-observational bodily-self-acquaintance, then it is unclear why it would be experienced as emanating from a psychophysical perspective at all. We contend that only if witness consciousness is experientially

\footnotetext{
9 Shoemaker would probably not agree with this modification of his argument; in his view, although mental predicates are absolutely immune to error through misidentification relative to the first-person pronoun, bodily predicates are merely de facto immune. For further discussion of this issue, see Legrand (2006); Chen (2009); Cassam (this volume); Bermudez (this volume).
} 
anchored to the body as an ordering frame of reference for perception and action can there be anything specifically subjective or perspectival in awareness.

Let us put this argument in a more Shoemaker-style form. To identify (in Shoemaker's sense) an object as perspective-lending requires finding something true of that object that one already holds true of one's perspective on the world (some distinguishing property that identifies the object as pertaining to one's unique perspective). Such object-identification, however, presupposes knowledge of the perspective in question. To avoid an infinite regresss, one must have some nonobservational, prereflective awareness of oneself as the relevant perspectiveholder, most fundamentally as a bodily subject. Hence nonobservational bodily awareness must belong originally to the subject of experience.

If our view is correct, then it poses a problem for Albahari's proposed distinction between subject and self, as well as the distinction between perspectival owner and personal owner. Prereflective bodily self-awareness entails an experience of boundedness, i.e., it entails a basic distinction within experience between one's subjective body (self) and one's phenomenal world (other). Consequently, by Albahari's proposed criteria, merely being a subject of experience will involve a basic sense of self. If the body belongs constitutively to the nature of perspectival awareness, then when the subject qua witnessing-from-a-psychophysical-perspective experiences the world, it does so as a 'natively unified' bodily subject.

In light of this point, let us consider some of the empirical considerations Albahari draws on to support her view. An important case study to which she appeals to support her distinction between perspectival and personal ownership is the pathology of somatoparaphrenia. ${ }^{10}$ Here the patient personally disowns a body part (say, the left arm) but still perspectivally owns the experience of the arm insofar as the arm appears in her visual field (2006: 55-56). The patient can recognize, with puzzlement, that the arm is joined to the rest of her body, while nevertheless denying that it is her arm.

Albahari sees in this pathology evidence for the possibility of dissociating perspectival from personal ownership. In our view, however, such pathologies constitute a breakdown of not only personal ownership but also perspectival ownership. To the extent that the patient no longer perceives the world with and through her personally disowned arm, the pathology includes a partial breakdown of the patient's subjective perspective on the world. As a consequence

10 Albahari refers to the pathology as anosognosia, but from her description of the symptoms it seems that somatopharaprenia is the precise condition she has in mind. Anosognosia is a patient's denial of her paralysis or disability, but is not usually accompanied by the denial that her arm is hers or part of her body. The patient will typically correctly assert that it is her arm, but will incorrectly assert that it is functioning perfectly when in fact it is paralyzed. Somatoparaphrenia occurs when the patient denies that the arm is hers and is usually accompanied by the claim that it belongs to someone else. 
of this impairment, certain affordances within her environment will no longer be present to the patient; for example, the teacup just to her left will no longer present to her as graspable-from-the-left. Although the arm will still be given in experience as an object (it will still appear as an object within her visual field), it will not be appropriately integrated into the sensorimotor capabilities of the body-as-subject and consequently no longer be part of her subjective perspective on the world.

Albahari (2006: 161) also contends that one can conceive of a global condition of depersonalization, in which the body continues to function properly, unlike limb paralysis in anosognosia. In such a case, she claims, one's whole body would be experienced as an object, rather than as integrated with the subject, and moreover the subject would still be able to interact with the world in the capacity of a perspectival owner.

Yet it is precisely the possibility of this scenario of global depersonalization that we mean to challenge with the above argument. Without one's body being experienced prereflectively as that in relation to which objects are situated, it would be impossible for a subject to experience a world of objects as external to one's subjective perspective (an ability that Albahari maintains is preserved in perspectival ownership). Therefore, to be a subject of experience even in the minimal sense of witnessing-from-a-perspective requires being prereflectively aware of oneself as a bodily subject.

This line of thought implies that perspectival ownership involves an experience of the body as belonging constitutively to the subject rather than as abject appropriated to the subject's witnessing perspective. Therefore, one's awareness of the body as belonging to the subject cannot be the result of the process of appropriation that Albahari describes. Identification-as-appropriation cannot occur at the level of the body-as-subject because the body is not given in experience originally as an object. Hence the primary metaphors Albahari uses to conceptualize the process of identification-as-appropriation seem inapt for understanding the nature of the body-as-subject. She states that appropriated objects present "a reflexive aspect" to the subject's experience and hence that one comes to view "the world through the lens of that aspect, such that its filter seems to become a part of the subject's first-person perspective" (2006: 93). Although the body is that by which the world shows up or comes into focus for a subject, it would be wrong to construe the body as an instrument through which one perceives the world. Such an image implies the problematic distinction between the observing subject and its body, and moreover is too disembodied and spectatorial to capture the lived body and its distinctive mode of transparency in world-directed experience (see Legrand 2007, this volume).

Might it be the case that we identify with the body-as-subject in some other way? We will return to this question in our conclusion. 


\section{Subjectivity and Boundedness}

One might object that we have moved too quickly from the conclusion that the body is fundamentally part of the subject of experience to the conclusion that all subjective experience is characterized by a sense of boundedness. After all, Albahari proposes that one can be free of the self-illusion, yet still be able to perceive and navigate the world as a perspectival owner. Although one might grant that prereflective awareness of one's body-as-subject is necessary for perspectival ownership, one might still deny that this kind of self-awareness implies boundedness in the sense that Albahari regards as constitutive of the self-illusion. To put the point another way, perhaps Albahari's notion of boundedness differs from the mere distinction in experience between bodily subject and worldly object-a distinction that would be preserved when the illusory sense of self is removed.

To meet this objection, we need to distinguish between a weak sense of boundedness and a strong sense of boundedness. Weak boundedness consists in the experiential distinction between one's bodily perspective and whatever is perceived from that perspective. Strong boundedness consists in the experiential distinction evinced by Albahari's four modes of self-identification-'this-importance-ofbeing-this-very-thing', 'agency', 'consistent self-concern', and 'personal ownership' (Albahari 2006: 94). These modes of self-identification, she conjectures, co-arise with the mindset of 'craving' and emotional investment. Consequently, each possesses an emotional valence (2006: 107-109). It is thus the differential value placed on being 'this very thing' that is symptomatic of a sense of self.

Let us note first that the way Albahari defines boundedness favours the weak sense. She states that boundedness consists in the property of being ontologically unique or distinct from everything else (2006: 90-91). This definition, however, is too inclusive for her purpose of showing that the self is an illusion whereas the subject is not, for just as there appears to be an ontological distinction between self and other, so too there is an experiential distinction between the perspectival subject and its intentional objects. Albahari states that she does not intend boundedness to be an attribute of the witnessing subject as such, but only of the witnessing subject that harbours a sense of personal selfhood (2006: 90). Nevertheless, if we understand 'boundedness' minimally as ontological distinctness or uniqueness, then despite her claim to the contrary, a (bodily) subject would seem as conceptually and experientially bounded as a self.

Albahari might reply that an experiential distinction between subject and object does not determine whether the subject in itself is bounded or unbounded. Specifically, she might argue that the subject-object distinction is extrinsic to the witnessing subject (witness consciousness), whereas a self would have to be intrinsically characterized by its ontological distinctness from everything else. 
Given that the subject is a bodily subject, however, boundedness cannot be extrinsic to the witnessing subject. Suppose we allow for purposes of argument the possibility of a pure witness consciousness with no sense of boundedness. Although boundedness would then be extrinsic to witnessing as such, it does not follow that boundedness would be extrinsic to witnessing qua subject. Defining 'subject' in terms of a psychophysical perspective (as Albahari does) implies that there is something that is perspectivally owned (one cannot have a point of view without something appearing within one's field of view). In this way, subject and object are constituted in relation to each other. Consequently, boundedness is intrinsic to the subject-object relation and therefore to the role of perspectival ownership.

This reasoning depends on the premise that the subject is constitutively bodily and not merely embodied. If one holds, however, that the subject is distinct from the body, then one could also hold, as Albahari apparently does, that a subject can have a completely impersonal awareness of its psychophysical perspective and hence that the experiential distinction between that perspective and what appears from that perspective is not a distinction inherent to the subject itself. Instead, this distinction would reside within the appearances that are given to the witnessing subject. Moreover, if there were a condition of pure objectless (and thus subjectless) witnessing (as is putatively the case in nibbanic consciousness), then, upon returning to one's life as a perspectival owner, the witnessing subject would have a sense that its status as a subject is a merely contingent one and hence recognize that it is not intrinsically confined to this role. Albahari appears to conceive of the subject's unboundedness in this way (2006; 57-58). ${ }^{11}$

Suppose now that what Albahari means by boundedness is not captured by her definition (which is too weak) but instead corresponds to what we have called strong boundedness. In other words, boundedness does not consist in the mere distinction between subject and object, but rather in the fundamentally evaluative distinction between a differentially important self and the rest of the world.

\footnotetext{
11 One might nevertheless object that conceptualizing the subject as unboundeded in the weak sense remains problematic. Specifically, even if we put aside the issue of whether or not the subject is constitutively bodily or merely embodied, one might claim that there will still remain a straightforward distinction between the witnessing subject and the experiences that are given to it. Consider that Albahari (2009) argues for a 'radical ontological distinction' between the stream of experience and the witnessing subject to which the stream of experience presents. If boundedness, however, refers simply to ontological distinctness, then calling the witnessing subject 'separate' and 'distinct' from the stream of experience will conflict with the thesis that the subject is inherently unbounded. Once again, although witnessing per se might be unbounded, witnessing qua subject would be inherently bounded, i.e., distinct in relation to that which is witnessed. Although this objection points to a weakness in Albahari's definition of boundedness, we do not intend to stress this point. It seems to us that the boundedness that one finds in the context of the bodily subject is more robust and a source of more substantive disagreement between us than the mere distinction between witness consciousness and the stream of experience that is witnessed.
} 
According to this interpretation, boundedness arises when the pre-existing nonevaluative boundary between one's subjective perspective and what is perceived from that perspective becomes distorted or exaggerated as a result of self-identification and 'craving'.

This interpretation captures much of what seems to motivate Albahari's differentiation of the subject as unbounded from the self as bounded. Consider her discussion of the mere perceptual differentiation between oneself and an emotionally neutral object, such as a blade of grass:

I still identify myself as something decisively separate from the blade of grass. It is reasonable to suppose that if the Buddhist theory is correct, then the ongoing mindset of tanha [emotional investment/craving], involving a constant (although not exclusive) lookout for 'number one', will be enough to create a general perceptual tropism, such that we involuntarily view even emotionally neutral items in our perceptual purview as decisively 'other' from the 'self' that perceives them. Tanha will thus, on the Buddhist position, fuel the subject's overall disposition to identify itself with the perspectival owner of its perceptions, such that the perceptions are felt as personally 'belonging' to the subject. (Albahari 2006: 181-182).

We find two lines of thought in tension here. According to the first, perceptual experience comprises a distinction between one's subjective perspective and whatever objects are perceived from that perspective, but this distinction gets accentuated and distorted through the process of craving-driven identification-asappropriation. The repeated use of 'decisively' in the passage above ("decisively separate" and "decisively other") suggests that what is illusory in the experience is not the separation between self and other per se, but rather the nature of the separation. The kind of boundedness in play here is strong boundedness: the experience of being a self results from one's disposition to imbue the self-world distinction with differential value and emotional significance, and thereby to reify what is actually a fluid boundary. According to the second, the basic differentiation in perception between one's subjective perspective and what appears from that perspective is already the result of object-appropriation and emotions of selfconcern. The problem with this line of thought, however, is that it conflicts with Albahari's thesis that one would still be able to perceive and act effectively in the world without a sense of self. If removing the sense of self entails removing the perceptual distinction between perceiver and perceived, then it will also eliminate perspectival ownership.

In summary, the concept of boundedness does not seem to provide a clear way of distinguishing between subject and self and establishing that the self is an illusion. Our overall impression from Albahari is that she conceives the experience of boundedness as something quite minimal, namely, the sense of being ontologically distinct from the surrounding world. But it is difficult to accept that what is primarily responsible for this minimal sense of distinctness is the same as what 
generates the four modes of evaluative self-identification ('this-ness', 'agency', 'consistent self-concern', and 'personal ownership'). Instead, the sense of being a bounded self seems more intimately connected to the experience of having a firstperson perspective that is constitutively related to the subjective experience of the lived body. Although the phenomenological boundary between self and other may be exaggerated or distorted as a result of a craving mind-set, it seems misleading to assert that experiences lacking this feature involve no sense of boundedness whatsoever. It seems more accurate to say that the boundary separating self and other, though still phenomenally manifest, is no longer reified.

\section{Conclusion}

We have argued that in order to be a subject of experience, in Albahari's sense of 'witnessing from a psychophysical perspective', one must be prereflectively aware of oneself as a living body, i.e., one must be a bodily subject. The argument we have given focuses on the ability to identify something as a perspective-lending object; we have suggested that this ability presupposes a more fundamental and distinctly subjective awareness of the living body as the locus of perspectival awareness. According to this line of thought, an object's status as 'perspective-lending' presupposes a prior prereflective and non-object-directed awareness of oneself as the perspective-holder. If this point is correct, then one's subjective bodily awareness is identification-free in both Albahari's and Shoemaker's senses. One does not identify one's body on the basis of observation and identification (in Shoemaker's sense); rather, one's body is known prereflectively and nonobservationally. Consequently, the body-as-subject cannot be the result of identification (in Albahari's sense), because the body is not given fundamentally an object of experience.

We have also argued that being a perspectival owner of experience suffices for a certain sense of boundedness. Prereflective bodily self-awareness comprises an experience of the basic distinction between one's subjective body and the phenomenal world. Consequently, according to Albahari's criterion, merely being a subject of experience involves a basic sense of self.

Although we have argued that the subject is bounded and hence a self, we do not thereby affirm that the self is a separately existing entity or thing (Albahari 2006: 90-91). Albahari frequently uses these words to convey that our everyday assumption of selfhood is substantialist in nature, i.e., that we implicitly take the self to be a thing whose nature is 'unconstructed' and that exists independently of its experiences and the rest of the world. Yet such a conception is hardly the only way to understand the self. 
On our view, the distinction between self and world is best understood as a mutually specifying relation that is enacted in the process of living (Thompson 2007). The selfhood of the living body is one that is continually reaffirmed through its bodily comportment within a milieu, an environment upon which it vitally depends and toward which it is of necessity normatively directed. Consequently, the self should not be conceived as a being that exists independently of its world, for neither self nor world exist or can be understood in abstraction from the other. Moreover, in arguing for the boundedness of the subject, do we assume that this boundary is fixed or inflexible. On the contrary, as phenomenologists and cognitive scientists have discussed, the felt boundary between subject and world is plastic and fluidly adaptive (Di Paolo 2009; Thompson and Stapleton 2009).

Hans Jonas's remarks about the organism as a living being can equally be applied to the self: "organisms are entities whose being is their own doing ... the being that they earn from this doing is not a possession they then own in separation from the activity by which it was generated, but is the continuation of that very activity itself" (Jonas, 1996: 88; see also Thompson 2007). As Mackenzie (2009) has recently argued, there is a connection between Jonas's conception of living being as a continuous activity of self-production and the Buddhist claim that the self arises from a process of self-appropriation (and, moreover, is nothing beyond this appropriative activity). Given this connection, a form of identification or 'Imaking' will be an ineliminable condition of living being. Moreover, this biological self-appropriation will be reflected phenomenologically in prereflective self-awareness as the experience of sentience or the feeling of being alive (Thompson 2007).

In conclusion, although we disagree with Albahari's account of how we come to identify with the body-as-subject (namely, as the result of object-appropriation), we do not deny that we identify with this body and that this identification is the outcome of processes of self-appropriation or self-constitution. Indeed, we agree that the lived body is something that we have a sense of being and that this kind of identification with the body is crucial for successful perspectival ownership. Although the selfhood of the bodily subject may be constructed through ongoing processes of self-appropriation, it does not follow that its status as a self is an illusion.

\section{REFERENCES}

Albahari, M. (2006) Analytical Buddhism: The Two-Tiered Illusion of Self. New York: Palgrave Macmillan.

Albahari, M. (2009) Witness consciousness: its definition, appearance, and reality. Journal of Consciousness Studies 16(1): 62-84.

Cassam, Q. (1999) Self and World. Oxford: Oxford University Press. 
Chen, C. (2009) Bodily awareness and immunity to error through misidentification. European Journal of Philosophy DOI: 10.1111/j.1468-0378.2009.00363.x

Descartes, R. (1986) Meditations on First Philosophy, with selections from the Objections and Replies, trans, J. Cottingham. Cambridge: Cambridge University Press.

Di Paolo, E. (2009) Extended life. Topoi 28: 9-21.

Gupta, B. (1998) The Disinterested Witness. A Fragment of Advaita Vedanta Phenomenology. Evanston, IL: Northwestern University Press.

Gurwitsch, A. (1966) A nonegological conception of consciousness. In A. Gurwitsch, Studies in Phenomenology and Psychology, pp. 287-300. Evanston, IL: Northwestern University Press.

Jonas, H. (1996) Mortality and Morality: A Search for the Good After Auschwitz. Evanston, IL: Northwestern University Press.

Legrand, D. (2006) The bodily self: The sensori-motor roots of pre-reflexive selfconsciousness. Phenomenology and the Cognitive Sciences 5: 89-118.

Legrand, D. (2007) Pre-reflective self-consciousness: on being bodily in the world. Janus Head 9 (1) 493-519.

MacKenzie, M. (2009) Enacting the self: Buddhist and Enactivist approaches to the emergence of the self. Phenomenology and the Cognitive Sciences DOI 10.1007/s11097o09-9132-8

Merleau-Ponty, M. (1962). Phenomenology of Perception, trans Colin Smith. London: Routledge Press.

Sartre, J.-P. (1991) The Transcendence of the Ego. New York: Hill and Wang.

SEARLE, J. (2000) Consciousness, free action, and the brain. Journal of Consciousness Studies $7(10): 3-22$.

Shozmaker, S. (1968) Self-reference and self-awareness. Journal of Philosophy 65: 555-567.

Shoemaker, S. (1984) Personal identity: a materialist's account. In S. Shoemaker and R. Swinburne (eds.), Personal Identity. Basil Blackwell.

Shoemaker, S. (1986) Introspection and the self. Midwest Studies in Philosophy 10: 101-120.

Siderits, M., Thompson, E., and Zahavi, D. (eds.) (2011) Self, No-Self? Perspectives from Analytical, Phenomenological, and Indian Traditions. Clarendon: Oxford University Press.

Strawson, G. (1997) The self. Journal of Consciousness Studies 4(5/6): 405-428.

Thompson, E. (2007) Mind in Life: Biology, Phenomenology, and the Sciences of Mind. Cambridge, MA: Harvard University Press.

Thompson, E. and Stapleton, M. (2009) Making sense of sense-making: reflections on enactive and extended mind theories. Topoi 28: 23-30.

ZAHAVI, D. (2002) First-person thoughts and embodied self-awareness: Some reflections on the relation between recent analytical philosophy and phenomenology. Phenomenology and the Cognitive Sciences 1: 7-26.

Zahavi, D. (2005) Subjectivity and Selfhood: Investigating the First-Person Perspective. Cambridge, MA: The MIT Press/A Bradford Book. 
Comp. by: PG2689 Stage : Proof ChapterID: 0001204475 Date:1/10/10

Time:16:18:31 Filepath:d:/womat-filecopy/0001204475.3D

OUP UNCORRECTED PROOF - FIRST PROOF, 1/10/2010, SPi 